\title{
A antropologia jurídica na Rússia contemporânea: a busca de um paradigma*
}

\author{
Legal anthropology in contemporary Russia: \\ the search for a paradigm
}

\section{Pavel Igorevich Kostogryzov Academia Russa de Ciências - Filial dos Urais}

Resumo Nas últimas duas décadas, estudos no campo da antropologia legal estão se desenvolvendo com vigor na Rússia. No entanto, o lugar dessa disciplina no sistema das ciências humanas e da sociedade ainda é assunto de debate. Entre os cientistas russos, não há unidade na definição de seu objeto e sujeito, e de sua estrutura como ciência, tampouco foi desenvolvido um aparato categorial aceito de modo generalizado. $\mathrm{O}$ conhecimento humano moderno, incluindo o antropológico, é caracterizado pela interdisciplinaridade. Isso, por um lado, abre perspectivas heurísticas amplas, mas, por outro lado, gera certas dificuldades no plano epistemológico, sendo a mais óbvia o problema de traduzir o conhecimento da linguagem de uma disciplina para a linguagem de outra. Uma vez que a pesquisa jurídica e antropológica é realizada tanto por juristas como por antropólogos, e muitas vezes por especialistas de outras ciências sociais, surge a necessidade, para se assegurar a sinergia dos esforços de pesquisa, de desenvolver uma linguagem de antropologia jurídica que seja única e inequivocamente compreendida por todos os cientistas, o que exige esforços concentrados de toda a comunidade de pesquisadores para a formação de convenções terminológicas. Isso requer uma discussão pública que envolva

* Artigo originalmente publicado em língua russa (título original: Юридическая Антропология в Поисках Парадигмы) no Anuário Científico do Instituto de Filosofia e Direito da Ural Branch of the Russian Academy of Sciences - 2017, Vol. 17, Edição 4, pp. 81-99. URL: http://yearbook.uran.ru. DOI 10.17506/ryipl.2016.17.4.8199. Traduzido por Olga Alyokhina Alves e revisado por Fernando César Costa Xavier. Nota do autor: O artigo foi elaborado com o apoio do projeto de pesquisa do IFD/RAS n 15-19-6-6 A transformação de reguladores morais, políticos e jurídicos da sociedade moderna: a interação de espaços nacionais e globais. 
uma ampla gama de cientistas provenientes de diferentes disciplinas, mas que estejam unidos por uma perspectiva comum de pesquisa, ou seja, uma perspectiva antropológica e jurídica. Descrevendo as principais abordagens metodológicas que coexistem na antropologia jurídica russa moderna, o autor descreve as linhas mais promissoras em que tal discussão poderia se desenrolar. Como uma das possíveis variantes, é apresentada a visão do autor sobre o objeto, o sujeito e a estrutura daquela ciência. É considerada uma das teorias mais promissoras, capaz de reivindicar o papel do fundamento filosófico da pesquisa antropológica legal jurídica, antropologia de energia [энергийная антропология].

Palavras-chave: Antropologia JuRídica. Antropologia do direito. Metodologia da ciência. Paradigma. Abordagem de pesquisa. Antropologia de energia.

Abstract Studies in legal anthropology have been actively developing in Russia during the last two decades. However, the place of this discipline among the humanities and social sciences is still under discussion. There is no consensus among Russian researchers about the definition of its matter, thematic field, and structure; its conventional categorical apparatus is not elaborated yet. The present-day studies in humanities, particularly in anthropology, are interdisciplinary. On the one hand, this peculiarity opens up broad heuristic prospects; on the other hand, it produces certain epistemological difficulties. The most obvious is the problem of transferability of knowledge from one discipline's language into another one. Since the legal and anthropological studies are conducted by both law scholars and anthropologists, as well as, by specialists in other social sciences, a common language of legal anthropology unambiguously understood by all scientists becomes necessary for ensuring synergy of their research efforts. This requires concerted activity of the whole research community in order to form terminological conventions. It presupposes public discussion with the participation of a broad circle of scholars who represents different fields of knowledge but are committed to the common legal anthropological research agenda. In characterizing the basic methodological approaches coexisting in contemporary Russian legal anthropology, the author outlines the most promising issues, which such discussion could develop. The author's vision of the object, the thematic field, and the structure of legal anthropology is presented as one of possible versions. One of the most promising theories claiming to become the philosophical foundation of legal-anthropological studies - the anthropology of energy - is considered.

Key-words: Legal anthropology. Methodology of science. Paradigm. ReSEARCH APPROACH. ANTHROPOLOGY OF ENERGY. 


\section{INTRODUÇÃO}

A "guinada antropológica" nas ciências sociais, que se concretizou na segunda metade do século XX, não ignorou a teoria do direito. A antropologia jurídica, graças às obras de autores como N. Rouland, passou a ocupar um lugar de honra entre as disciplinas jurídicas. A teoria do direito russa, que se encontrou em uma situação de crise metodológica como resultado do colapso do paradigma marxistaleninista, anteriormente considerado como "o único verdadeiro", voltou-se para a antropologia no final da década de 1990. A despeito disso, nas últimas duas décadas, monografias e livros, ou mesmo teses (como a tese de doutoramento de O. Puchkov [PUCHKOV, 2001]), sobre a antropologia jurídica, seu estatuto epistemológico e seu lugar nas ciências humanas e sociais, ainda são temas em debate.

Na Rússia, a antropologia jurídica desenvolveu-se em duas linhas paralelas. A primeira delas existe há bastante tempo como uma subdisciplina da antropologia social (cultural). Suas "bases foram estabelecidas no século XIX, mas na era soviética o número de estudos nesta área declinou drasticamente, e essa subdisciplina [...] começou a se recuperar somente na década de 1990" (SOKOLOVSKY, 2015: 147). Os esforços de pesquisa da comunidade científica formados em torno dessa área concentram-se principalmente no estudo do direito consuetudinário e da vivência jurídica dos povos indígenas. A maioria dos pesquisadores adere ao paradigma tradicional de antropólogos e etnógrafos, em que o estatuto da antropologia jurídica como uma das "seções" ou subdisciplinas da antropologia cultural é considerado uma questão resolvida há muito tempo, não mais discutida.

A segunda linha - muito mais recente - começou a se formar na segunda metade da década de 1990, dentro da comunidade científica de juristas, e o seu processo de formação ainda não foi concluído. Os pesquisadores que seguem essa tendência veem muitas vezes a antropologia jurídica como uma entre as ciências jurídicas, ou "um ramo situado no âmbito da teoria geral do direito" (KOVLER, 2002: 20). 
Nesta abordagem, por sua vez, existem dois pontos de vista. Os partidários do primeiro, em particular A. I. Kovler e V. S. Nersesyants, veem a antropologia do direito como uma disciplina científica e pedagogicamente independente, ao lado de outras ciências jurídicas fundamentais. "No plano das ciências jurídicas e da educação jurídica, a antropologia jurídica ocupa seu lugar especial e independente entre uma série de disciplinas científicas gerais como a teoria do direito e do Estado, a filosofia do direito, a sociologia do direito, a psicologia do direito, a história do direito, do Estado e do pensamento jurídico, e o direito comparado" - nesse sentido, tem-se o trabalho de V. S. Nersesyants (NERSESYANTS, 1999: 2).

Os cientistas que possuem um ponto de vista diferente desse não reconhecem a antropologia do direito com um tal status [de disciplina autônoma], insistindo que é uma abordagem filosófica e metodológica encerrada dentro da teoria geral do direito e da ciência jurídica em geral. No sentido dessa posição, por exemplo, há a monografia coletiva recentemente publicada "Antropologia sociocultural do direito", que talvez seja o trabalho mais fundamental, na ciência russa, até os dias de hoje, sobre a questão. Para eles, "a antropologia sociocultural do direito não é uma disciplina científica institucionalizada e independente, mas uma abordagem específica de análise e representação da realidade jurídica, mais profunda do que a praticada pela teoria dogmática do direito. Não é necessária uma institucionalização especial dessa disciplina" (ISAEV; CHESTNOV, 2015: 162).

Assim, pode-se afirmar que, atualmente, duas direções para a antropologia jurídica coexistem. Elas podem, sob certas condições, ser chamadas de "antropológica" e "jurídica". E os seus paradigmas fundantes - bem estabelecidos no caso da "antropologia jurídica antropológica" e localizados em um estágio inicial de formação no caso de seu homólogo "jurídico" - são tão diferentes que não parece muito exagerado falar da possibilidade de surgimento de duas ciências diferentes com o mesmo nome. Estão sendo formadas em torno delas comunidades científicas, cujas composições, na prática, não apenas não se cruzam, como também, muitas vezes, ignoram as conquistas das pesquisas umas 
das outras. É difícil reconhecer essa situação como desejável. Há uma necessidade de tentar "fechar a lacuna" formada entre "dois [tipos] de antropólogos do direito". E não se pode dizer que esse trabalho não está sendo encaminhado. Na virada da década de 1990/2000, foram realizados cursos de verão sobre antropologia jurídica, no âmbito dos quais teve lugar um diálogo entre antropólogos e juristas; no Instituto de Etnologia e Antropologia da Academia Russa de Ciências há, inclusive, um seminário a respeito de antropologia jurídica (NOVIKOVA, 2016: 125). No entanto, esses esforços ainda não levaram à formação de um único paradigma.

Em busca de um caminho para a convergência de posições, pode servir de orientação a seguinte observação de I. L. Chestnov: "qualquer que seja a abordagem professada, não se nega a existência de uma antropologia sócio-cultural (ou social) do direito institucionalizada" (ISAEV, 2015: 162). Isso pressupõe a existência da antropologia jurídica em duas "hipóstases" ("unостасяx") - como orientação epistemológica na teoria do direito e como - na terminologia dos autores - uma independente e institucionalizada disciplina científica. Em nossa opinião, é esse pensamento que indica o caminho para a síntese de pontos de vista aparentemente inconsistentes sobre a questão do status científico da antropologia do direito.

Para determinar o lugar da antropologia jurídica (no segundo sentido, como disciplina científica independente) na ciência social e humana, antes de tudo, é necessário descobrir qual é o seu objeto de estudo. N. Rouland define essa ciência como "uma disciplina que por meio da análise da palavra escrita ou falada, prática e sistema de representação, estuda os processos de juridicização peculiares de cada sociedade e procura revelar sua lógica interna" (ROULAND, 1990: 7).

De acordo com essa definição, o objeto de estudo da antropologia do direito é o "processo de juridicização" com sua "lógica interna" inerente, levando em consideração a variação geográfica, cultural, histórica etc. ("peculiares de cada sociedade"). "Processos de juridicização" significam, por sua vez, que "cada sociedade [...] escolhe quais regras de conduta que já operam em outros sistemas de controle so- 
cial (por exemplo, a moralidade ou a religião) podem ser qualificadas (ou não qualificadas) como jurídicas" (ROULAND, 1990: 8). É difícil reconhecer essa definição como exauriente, uma vez que, por toda a importância desses processos, seria inadequado limitar para eles apenas o campo de estudo da antropologia jurídica.

Entre os cientistas russos, não há unidade para determinar o objeto de estudo da antropologia do direito. Assim, V. V. Bocharov considera que "geralmente um sistema jurídico (um invariante do direito consuetudinário) se forma no processo de auto-organização social e determina a ordem social em uma sociedade tradicional" (BOCHAROV, 2013: 16; grifos do autor). Em nossa opinião, tal abordagem restringe injustificadamente o campo científico da matéria, reduzindo-a, de fato, à etnografia jurídica. Em primeiro lugar, a antropologia jurídica estuda não apenas a sociedade tradicional, mas também a moderna. Isto, por sinal, é claramente demonstrado pelo próprio trabalho de V. V. Bocharov, do qual esta definição é tomada: nele, o autor investiga a ação da "lei não escrita" na sociedade moderna com não menos cuidado do que na tradicional, ampliando assim os limites do declarado objeto de estudo. Em segundo lugar, é difícil concordar com o autor na definição de que a antropologia do direito deveria estar interessada exclusivamente naquele sistema que é geralmente jurídico (e que, na opinião dele, é um "invariante do direito consuetudinário"). Muitos pesquisadores, começando por N. Rouland (ROULAND, 1999), mostraram de forma convincente que a antropologia jurídica deve considerar uma pessoa no contexto do direito tanto costumeiro quanto escrito, sem o que é impossível criar um modelo holístico de Homo juridicus.

Os autores do trabalho "Antropologia sociocultural do Direito" acreditam que "o objeto científico da antropologia sócio-cultural do direito é o direito como um fenômeno social em todas as suas múltiplas facetas, ou a realidade jurídica, isto é, as pessoas socializadas em uma determinada cultura construindo as noções sociais prevalentes do direito, incluindo sua incorporação simbólica na legislação e outras formas de direito normativo, bem como, sua implementação em práticas legalmente significantes" (ISAEV; CHESTNOV, 2015: 121; grifos do 
autor). Nesta definição, os conceitos desiguais associados naqueles termos "ou" e "isto é" são impressionantes. O direito, mesmo que tomado "em todas as suas múltiplas facetas", é idêntico à "realidade jurídica", e, por conseguinte, é "para pessoas que constroem [...] noções sociais sobre o direito"? Se assim for, o objeto da antropologia jurídica dentro do quadro de uma definição seria determinado de três maneiras(!), que não podem deixar de causar confusão no leitor.

De acordo com O. A. Puchkov, "a antropologia jurídica estuda $o$ direito como um problema humano" (PUCHKOV, 1999: 90; grifos do autor). A. I. Kovler, a partir da definição de antropologia jurídica dada por N. Rouland, formulou a sua própria em duas versões - desenvoltas e breves. Aqui apresentamos a segunda versão: "A antropologia jurídica estuda a existência jurídica do homem em todos os estágios de desenvolvimento desta existência, desde o arcaico até o moderno" (KOVLER, 2002: 23; grifos do autor). N. I. Novikova associa-se a ele: "a antropologia jurídica estuda a existência jurídica das pessoas" (NOVIKOV 2016: 128; grifos do autor). O objetivo da antropologia do direito foi definido pelo acadêmico V. S. Nersesyants da mesma forma. "A antropologia jurídica", escreveu ele, "é a ciência do homem como um ser social nas suas manifestações jurídicas, por suas dimensões e características" (NERSESYANTS, 1999: 1; grifos do autor).

Em última instância, simplificando, é possível reduzir a diversidade dos pontos de vista expressados por diferentes cientistas e escolas de pensamento na discussão sobre o objeto da antropologia do direito, para duas posições fundamentais: uma considerando que é uma ciência principalmente acerca do direito, outra, principalmente a respeito do homem. A primeira posição, entre os pesquisadores russos, foi apresentada por V. Bocharov e os autores da monografia "Antropologia sociocultural do Direito"; a segunda, por V. S. Nersesyants, A. I. Kovler e todos os cientistas pertencentes à corrente "antropológica" da antropologia jurídica. O ponto de vista de O. A. Puchkov pode ser considerado como um compromisso com um meio-termo, mas, em nossa opinião, ainda está mais próximo da segunda opção. 
Ao escolher entre as duas posições indicadas, duas considerações fundamentalmente importantes devem ser consideradas. Primeiro, em relação ao próprio nome da ciência - "antropologia jurídica" ou "antropologia do direito". A antropologia é, por definição, a ciência do homem, e a disciplina que tem um objeto tão distinto simplesmente não pode aludir a algo diverso, não importa qual epíteto exista depois. Portanto, é justo admitir que o objeto de estudo da antropologia jurídica é precisamente o homem, e não outra coisa. Em segundo lugar, é necessário levar em conta que a antropologia jurídica como subdisciplina da antropologia cultural já existe há muito tempo, e podemos falar sobre a expansão de seu campo temático, o seu enriquecimento metodológico por meio de uma interação mais próxima com a ciência jurídica, ou talvez a sua reinstitucionalização em razão de uma separação mais precisa com outras subdisciplinas da antropologia, o uso de novas abordagens e a construção de um novo paradigma, mas não acerca da criação de outra ciência com o mesmo nome - talvez, sim, um objeto de estudo diferente.

Portanto, é necessário separar a antropologia jurídica como uma disciplina científica independente ("antropologia do direito institucionalizada" de acordo com I. L. Chestnov (ISAEV; CHESTNOV, 2015: 162) e a abordagem antropológica (antropocêntrica) na teoria do direito. Para a última, Pavlov usa o termo "conceito antropológico do direito" (PAVLOV, 2014: 167).

Agora, temos que descobrir qual é a especificidade da antropologia jurídica em comparação com outras ciências humanas. A antropologia geralmente é entendida como um conhecimento integral sobre o homem. Mas, por sua vez, uma pessoa é um objeto tão complexo que é impossível estudá-la de forma abrangente no âmbito de uma única ciência, que, ao mesmo tempo, pudesse preservar a unidade do sujeito e da metodologia. Portanto, a antropologia também pode ser vista como uma espécie de conceito "guarda-chuva" ("зонтичное" понятие), que reúne muitas disciplinas científicas relativamente independentes: antropologia física, cultural, política etc. E, entre elas, também estaria a antropologia jurídica. Unem-nas o seu objeto comum de estudo (o homem), embora cada um dos ramos da antropologia 
tenha sua própria tematização particular de pesquisa e sua própria metodologia para abordá-la.

A antropologia jurídica é uma ciência, em primeiro lugar, a respeito de pessoas e, apenas em segundo momento, sobre o direito. Isso nos permite traçar uma linha clara entre ela e as assim compreendidas ciências jurídicas. No foco da teoria do direito (mesmo quando considerada com posições antropologicamente consistentes) está o direito; não obstante o objeto de estudo da antropologia, inclusive a jurídica, permanece sempre sendo o homem. Quando um jurista estuda o indivíduo (o homem), ele observa suas características jurídicas inerentes; quando um antropólogo analisa o direito, ele enxerga o indivíduo que o criou. Podemos dizer que a antropologia do direito é uma visão do homem por meio do prisma do direito. Suas tarefas são o estudo da existência jurídica do homem e a busca das "raízes humanas" do direito - isto é, das facetas da existência humana no direito, que são "descartadas" do campo de visão, por um lado, dos outros ramos da antropologia e, por outro, da teoria do direito.

Dessa forma, a antropologia jurídica é uma ciência humana, ao lado de outras disciplinas antropológicas. O seu objeto de estudo é diferente do objeto da teoria do direito. A antropologia do direito "alimenta" a ciência jurídica com ideias, dota-a com ferramentas metodológicas, fornece a ela fatos científicos, recomendações práticas, mas não é, em sentido estrito, uma parte dela.

Assim, o objeto de estudo da antropologia em geral e da antropologia jurídica em particular é o homem. A construção do conceito de homem em todas as suas múltiplas facetas é tarefa da antropologia filosófica. Cada uma das disciplinas antropológicas especiais submete o objeto comum a elas a uma redução necessária. No caso da antropologia do direito, essa redução parece do seguinte modo: homem (человек) - homem-no-direito (человек-в-праве) - homem jurídico (человек юридический) - sujeito de direito (субъект права).

A antropologia jurídica não pode pretender "compreender" o objeto de estudo "homem" em toda a sua completude ontológica, mesmo porque isso não é afirmado por qualquer dos "ramos da antro- 
pologia", mas pode destacar as facetas inacessíveis à ótica de outras disciplinas antropológicas. Portanto, ela enfoca a atenção em um lado específico daquele objeto, que é o homem-no-direito. A antropologia do direito, ao considerar uma pessoa imersa na existência jurídica, tenta não perder qualquer dos aspectos da existência humana que de algum modo se manifestam nele (homem) e interagem com ele. O passo seguinte na redução é um homem jurídico (Homo juridicus) - um "produtor" e um "consumidor" de direito que interage no campo jurídico com outras pessoas e entidades extrapessoais (entidades estatais, jurídicas etc.). Aqui, é necessário levar em conta não só a influência unilateral do criador sobre sua criatura, mas também o oposto: o homem é uma criatura culturalmente condicionada, o que significa que sua personalidade é formada pela cultura, incluindo-se o direito como um dos componentes culturais. Portanto, ao contrário do homem-no-direito, que é um fenômeno universal, um homem jurídico existe em uma variedade de manifestações civilizacionais, regionais e nacionais. Cada cultura jurídica corresponde à sua "subespécie" Homo juridicus.

O último ponto de redução - o sujeito de direito - é realmente um conceito jurídico, um objeto comum de estudo para a antropologia do direito e para a ciência jurídica; é uma "pessoa normativa" (человек нормативный), conforme fixado nas normas do direito positivo.

O tema da antropologia jurídica é a existência jurídica do homem em todas as suas múltiplas facetas, o que juristas russos prérevolucionários chamaram de "vida jurídica". Esse tema pode ser definido de forma mais estrita como o comportamento de uma pessoa (tanto um indivíduo como uma comunidade de diferentes ordens) no campo jurídico, condicionada pelo contexto de uma cultura particular, com variáveis e invariantes inerentes a ela. A última observação é, até certo ponto, um reflexo das palavras de V. V. Bocharov (BOCHAROV, 2013:16) sobre o "direito consuetudinário invariante": na nossa opinião, a invariância no comportamento humano, inclusive jurídico, certamente existe. E a antropologia do direito, como qualquer disciplina antropológica, inclui entre suas tarefas a identificação de tais 
invariantes. Mas, ao mesmo tempo, a variação que a investigação pode apontar não é menos interessante a ela.

As tarefas da antropologia jurídica, em sua forma mais generalizada, são aprender o comportamento jurídico de pessoas de diferentes culturas e, com base nesse conhecimento, identificar aqueles traços universais que definem o quadro do comportamento jurídico inerente ao modo de pensar do Homo sapiens. Em geral, a questão de saber se a antropologia do direito busca por traços universais ou diferenças, acompanha essa ciência desde a sua origem. Se, antes do meio do século XX, os antropólogos se inclinavam para a primeira variante da resposta, na segunda metade prevaleceu a posição de relativismo cultural: os cientistas se concentraram nas diferenças - um homem de uma sociedade tradicional em relação a um de uma não tradicional, um africano em relação a um europeu, e assim por diante. Em formas extremas, esse relativismo vem reforçar a afirmação de total disparidade entre as experiências cultural e social de pessoas pertencentes a diferentes civilizações. Parece haver chegado o momento de uma abordagem mais equilibrada. Em nossa opinião, essas características de uma existência que tem características universalmente jurídicas e é única para cada cultura são fundamentalmente importantes, embora as primeiras sejam aprendidas somente após um exame minucioso da última. Portanto, estudos específicos de culturas jurídicas (que estão comprometidos com etnografia jurídica) devem preceder a construção de modelos generalizadores.

Sem tentar delinear exaustivamente o campo de estudos da antropologia jurídica, gostaria de registrar o significado especial que tem para ela o tema da consciência jurídica. Se na teoria do Estado e do direito ele é periférico, na antropologia jurídica deve, em nossa opinião, tornar-se um dos temas centrais. Apesar da disponibilidade de monografias e dissertações, ou mesmo teses de doutorado, sobre o assunto, os problemas de consciência jurídica não podem ser considerados suficientemente estudados. O fato é que, sendo um problema não tão jurídico quanto é humano, não pode ser exaustivamente estudado pelos métodos de uma teoria "pura" do direito, que inevitavelmente faz abstração do "background" sociocul- 
tural dos fenômenos jurídicos. Então, é a antropologia do direito que deve dar um contributo significativo para o estudo desse fenômeno.

Para efetivamente resolver as tarefas cognitivas que os confrontam, cada ramo do conhecimento deve ser organizado de certa maneira. Para O. A. Puchkov, a estrutura da antropologia jurídica é vista do modo seguinte: 1) teoria (parte geral) da antropologia jurídica; 2) antropologia jurídica da sociedade moderna; 3 ) antropologia jurídica das sociedades tradicionais (etnografia jurídica) (PUCHKOV, 1999: 5). A questão que então surge é: a linha entre sociedades modernas e tradicionais é tão imperceptível e os métodos de estudá-las tão diferentes que é necessário destacar para eles seções separadas entre as disciplinas científicas? Afinal de contas, os métodos etnográficos são válidos para qualquer sociedade humana, independentemente do estágio histórico de sua existência.

Se seguimos a lógica da construção de disciplinas jurídicas, é mais razoável distinguir, em primeiro lugar, as partes gerais (teóricas) das especiais. Então, é óbvio que a segunda tarefa é observar a realidade jurídica, coletar e sistematizar a informação, sendo a primeira a generalização teórica e conceituação dos conhecimentos apreendidos. Na parte especial, por sua vez, é possível separar subsecções para o estudo de sociedades que deixaram de existir (antropologia histórica do direito) e sociedades existentes (etnografia jurídica), uma vez que os métodos de estudo são realmente diferentes; por último, a antropologia jurídica das sociedades modernas e tradicionais (ou, como sugerem alguns autores, a antropologia do direito positivo e consuetudinário), a antropologia das subculturas jurídicas etc.

Uma das características mais importantes de qualquer disciplina científica e que determina seu status epistemológico é seu método de cognição. Uma discussão aprofundada sobre os métodos da antropologia jurídica exigiria, no mínimo, outro artigo, de modo que, sem abordar detalhadamente tal questão, observemos apenas a sua propriedade, comum a todas as ciências humanas e diretamente relacionada às ferramentas metodológicas utilizadas, sob a forma de uma natureza fundamentalmente interdisciplinar. 
O campo de pesquisa de cada uma das disciplinas antropológicas interage com o campo de pesquisa de pelo menos outra ciência - biologia, cultura, ciência política, jurisprudência - como refletido em seus nomes: antropologia cultural, antropologia política etc. Essa "dualidade" é expressa em como essas disciplinas constroem seu objeto e que métodos elas utilizam.

A síntese interdisciplinar é altamente característica do estágio moderno do desenvolvimento da ciência em geral e das humanidades em particular. Essa etapa pressupõe "a reorganização de todo o conhecimento científico e sua produção não tanto em uma base disciplinar como em um princípio problemático ou orientado para o problema" (SOKOLOVSKY, 2000: 52). A interdisciplinaridade é uma propriedade inerente às ciências humanas, e mesmo a divisão da antropologia em vários ramos relativamente independentes não priva cada um deles dessa característica. A antropologia jurídica não pode atuar sem fazer uso das ferramentas cognitivas de uma série de ciências - não apenas a teoria do direito e a antropologia, mas também a etnografia, a história, a ciência política, a linguística, a psicologia e a sociologia.

A interdisciplinaridade da pesquisa antropológica, por um lado, sem dúvida, abre grandes perspectivas heurísticas e, por outro lado, gera certas dificuldades no plano epistemológico, sendo o mais óbvio o problema de traduzir o conhecimento de uma disciplina com linguagem própria para a linguagem de outra disciplina.

Uma vez que a pesquisa jurídica e antropológica é conduzida tanto por especialistas do direito como por antropólogos, e muitas vezes também por especialistas de outras ciências sociais, para garantir a sinergia de seus esforços de pesquisa, torna-se necessário desenvolver uma única linguagem, que seja entendida inequivocamente por todos os participantes dessa comunidade interdisciplinar. Isso é possível enquanto resultado de uma atividade que tenha como propósito a formação de "convenções terminológicas", que implicam uma discussão pública envolvendo uma ampla gama de cientistas oriundos de diferentes disciplinas, mas unidos em torno de problemas antropológicos e jurídicos comuns de pesquisa. $\mathrm{O}$ início de tal discussão foi estabelecido 
na década de 1990. Com efeito, cada publicação sobre o assunto fornece a ela (discussão) uma ou outra contribuição. A despeito disso, até o presente momento, a discussão tem sido conduzida mais como monólogo do que como diálogo: cada autor oferece suas definições dos conceitos básicos, os quais são apenas parcialmente correlacionados com a terminologia usada pelos seus colegas.

Gostaria de crer que essa discussão será revivida e conduzida a um novo patamar, envolvendo uma troca ativa de ideias e o desenvolvimento de um consenso sobre as "constantes terminológicas" básicas que constituem o "quadro categorial" (RYAZANOVA, 2013: 38) da disciplina científica.

Sem pretender prejudicar os contornos básicos deste "quadro", permita-nos tomar a liberdade para indicar algumas direções do curso possível da discussão, e também para identificar pelo menos alguns termos que, na nossa opinião, são nodais para a alegada linguagem convencional da antropologia jurídica.

Obviamente, a pedra angular dessa disciplina científica são os termos "homem" e "jurídico". Todavia, essas categorias são tão complexas e multifacetadas que sua definição causa controvérsia incessante, mesmo no âmbito da antropologia filosófica e da teoria do direito, respectivamente. Portanto, é apropriado considerá-los como metacategorias de categorias da antropologia jurídica, não determinadas pelos meios epistemológicos dessa ciência em si mesma. O desenvolvimento delas continua a ser uma prerrogativa da filosofia - a antropologia filosófica e a filosofia do direito, respectivamente. Na antropologia jurídica, as escolas científicas podem coexistir, e os limites entre elas passam principalmente ao longo da linha de compreensão daquelas categorias básicas. Ao mesmo tempo, é necessário indicar claramente qual ideia sobre o homem e o direito é defendida pelo autor de um estudo particular.

Por que a clareza nesse assunto é tão importante, em nossa opinião? O fato é que as ideias filosóficas colocadas na base da pesquisa científica, em grande parte, determinam a direção em que ela irá se desenvolver e os pontos de referência aos quais a topologia do conhe- 
cimento científico produzido será atrelada. E, portanto, é importante, antes de tudo, para o próprio pesquisador, que essas ideias sejam enquadradas em um conceito claro. As categorias "limitantes" de tal conceito, no caso da antropologia jurídica, são, como já dito, os conceitos de "homem" e "direito". A partir do que exatamente as ideias sobre homem e direito serão consideradas pelo autor para o seu ponto de partida e toda a estrutura de seus argumentos, depende, em última instância, o conteúdo das conclusões a que ele chegará como resultado da pesquisa. A primeira função que essas categorias são chamadas a realizar na pesquisa antropológica e jurídica - chamemo-la de calibragem - é permitir isolar objetos de seu mundo fenomêmico, isto é, é distinguir inequivocamente gente (людей) de não-gente (не-людей) e fenômenos jurídicos (правовые явления) de não-jurídicos (не-правовых).

E se, a despeito de todas as volumosas diferenças na compreensão do conceito de "homem", há certo consenso a respeito dele - todos os antropólogos concordam ${ }^{1}$ sobre quem é exatamente considerado uma pessoa (pelo menos quando se trata de pessoas modernas e não de seus antepassados fósseis) - com o termo "direito" é diferente.

As definições de direito existentes na ciência jurídica moderna, sendo de conteúdo diverso, variam em volume, de modo que, dependendo de qual deles constitui a base de tal ou tais discursos jurídico-antropológicos, haverá muitos fenômenos qualificados como jurídicos. Isso deve ser levado em conta sempre que se trate de esclarecer o que exatamente deve constituir o campo de estudo da antropologia jurídica. Em vários autores, escolas científicas e correntes, seus limites serão diferentes dependendo da definição de direito que eles adotaram.

A segunda função realizada pela metacategoria da antropologia do direito é, na verdade, epistemológica. Pode até ser mais importante do que a primeira e, nesse caso, o papel principal é desempenhado não pelo volume, mas pelo conteúdo dos conceitos "homem" e "certo", uma

\footnotetext{
Nós deliberadamente deixamos para trás o debate das entrelinhas sobre se são seres humanos o embrião humano, o clone ou conceitos marginais que negam status humano para alguns representantes da espécie Homo sapiens (por exemplo, para pacientes com síndrome de Down). (N. do A.).
} 
vez que ele define o vetor da busca científica, direcionando-a para determinado rumo.

Paradoxalmente, a maior parte do trabalho acerca de antropologia jurídica (mesmo o mais fundamental, que seja considerado um clássico) não revela explicitamente as concepções de homem que estão em suas bases. Aparentemente, seus autores estão satisfeitos com a compreensão intuitiva de homem (a sua própria e a do leitor), que lida bem com a primeira - a função de "calibragem", mas não pode ser suficiente para construir um projeto epistemológico holístico que seja o núcleo organizador de toda a teoria científica. Isso não significa que os antropólogos não tenham (direito a) uma ideia clara sobre pessoa, até porque ela está certamente presente, ainda que, na maioria das vezes, de modo "invisível", cabendo ao leitor reconstruí-la a partir de informações indiretas. Os trabalhos a respeito de antropologia jurídica poderiam ser muito melhores se seus autores revelassem suas posições filosóficas na introdução ou no capítulo inicial de seus trabalhos.

Uma honrosa exceção quanto a isso foi a obra coletiva "Antropologia Sóciocultural do Direito", na qual consta o capítulo de autoria de V. I. Pavlov (ISAEV, CHESTNOV, 2015: 109-116; 301-337), o qual descreve brevemente o conceito de homem, que é a base sobre a qual vai discorrer o autor. Isso é apresentado de forma ainda mais detalhada nos trabalhos individuais do citado autor (PAVLOV, 2012a; 2012b; 2014). Ao contrário da maioria dos trabalhos acerca de antropologia jurídica, tanto nacionais quanto estrangeiros, cujos autores estão afastados de ideias behavioristas, freudianas ou marxistas a respeito do homem, a teoria antropológica original foi escolhida como base filosófica daquela obra.

Essa teoria original - os autores a chamam de energia ou sinérgica - é desenvolvida pelo renomado filósofo e antropólogo russo S. S. Khoruzhy e seus seguidores. Ela se origina do ensino antropológico e da prática ascética de direção axial na teologia ortodoxa medieval - o hesicasmo (исихазма) (cf. obras de João Damasceno, Gregório Palamas etc.). A antropologia hesicasta, por sua vez, tem origens na filosofia de Aristóteles, estendendo um fio de continuidade por meio das obras de Boécio e Orígenes. 
Uma antropologia de energia é caracterizada pela rejeição das tentativas de "captar" a essência do homem como se ela fosse algo estático, pronto e acabado (o que geralmente é característico do discurso antropológico moderno desde os existencialistas, os quais mostraram que a essência do homem é a sua existência: - a existência precede a essência), e pela transição para a construção de um modelo dinâmico de homem - o qual não se tornou, mas está se tornando, desse modo, um participante ativo do processo, criando-se a si mesmo (autopoiese). Esse processo é ancorado no conceito de energia; com efeito, um homem, na ótica hesicasta, não passa de um "pacote", um "coágulo" de energias difusamente dirigidas.

V. Pavlov, seguindo S. S. Khoruzhy, define a essência da compreensão energética do homem da seguinte forma: "A energia é a atualização da potencialidade daquilo que existe, e, como observado por S.S. Khoruzhy, 'com exatidão - corresponde ao próprio processo, ao movimento e à atualização das atividades, e não ao seu resultado (atualidade, realização)'. De acordo com Joan Damascene, 'todas as habilidades do homem [...] tanto cognitivas como vitais, bem como, na-

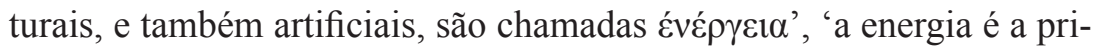
meira força natural e em movimento da alma racional'. O que caracteriza o não essencial, ou melhor, a descrição não-essencial de uma pessoa, é que o ascetismo, como resultado de uma observação de uma pessoa experiente, tem complementado, desenvolvido e refinado o conceito de energia - um homem de energia [...] passou a ser considerado como uma multiplicidade em constante mudança, um elemento de fracionalidade e variabilidade" (PAVLOV, 2012 b: 16).

Assim, a antropologia de energia é uma "abordagem dinâmica do homem em sua natureza, uma configuração antropológica dinâmica" (KHORUZHY, 2002). Rejeitando a busca inerente ao cientificismo vulgar por padrões lineares inequívocos, como os de causa e efeito, ela "coloca princípios morais e volitivos no centro" (KHORUZHY, 2002). Essa atitude epistemológica é inteiramente complementar à antropologia jurídica, que também presta muita atenção ao papel da moral e 
da força de vontade em uma pessoa "responsável" para a geração de fenômenos jurídicos.

No entanto, a escolha da antropologia de energia como o "fundamento" filosófico da pesquisa jurídico-antropológica está longe de ser óbvia. A teoria de S. Khoruzhy e de sua escola de pensamento pode parecer demasiado original, até mesmo exótica; também é possível censurar nela alguns arcaísmos, porque as ideias de antropologia de energia são ancoradas no corpo de textos filosóficos bizantinos de mais de seis séculos.

No entanto, em nossa opinião, essas obscuridades podem ser facilmente dissipadas. A natureza arcaica da antropologia de S. S. Khoruzhy é somente aparente. Toda a tradição filosófica europeia remonta genealogicamente a Aristóteles, e o hesicasmo bizantino faz parte de um "mainstream" intelectual pan-europeu em seu sentido mais amplo. $\mathrm{O}$ fato de que a tradição da filosofia hesicasta em certo momento foi interrompida e permaneceu por muito tempo no esquecimento, não pode servir de argumento contra sua atualização em uma nova época.

Há um "ponto de contato" entre a antropologia de energia e uma série de conceitos pós-clássicos que estão entre as mais relevantes ideias da moderna filosofia ocidental e das ciências sociais em geral. De modo particular, o próprio S. S. Khoruzhy aponta certas conotações dela na filosofia de M. Heidegger (KHORUZHY, 2012: 44). Paralelos com a visão existencialista da existência humana já foram mencionados. E há pontos óbvios e comuns com a filosofia oriental - tanto da Índia quanto do Extremo Oriente -, onde conceitos próximos do conceito-chave de energia também desempenham um papel de destaque, inclusive na compreensão do homem como fenômeno.

Do ponto de vista da antropologia jurídica, é de interesse particular o paralelo encontrado entre as ideias da antropologia de energia e as teorias mais relevantes para a ciência universal, voltadas para estudos práticos da vida social do ser humano, incluindo a sua vida jurídica. Em particular, estamos falando dos ensinamentos do sociólogo francês Pierre Bourdieu, que não só é um dos principais expoentes da sociologia contemporânea, como também tem um impacto na pesquisa 
antropológica. Os seus conceitos-chave do agente social, praticante e habitus se encaixam, tanto quanto possível, no paradigma energético.

Introduzindo a noção de "agente", em vez dos termos usuais "sujeito" ou "indivíduo", P. Bourdieu enfatiza "antes de tudo, essas qualidades [da pessoa], tais como a atividade e a capacidade de agir, e de ser detentora de práticas de certo tipo" (SHMATKO, 1993: 14-15). A categoria "energia" é ideal para descrever aquelas qualidades e sua implementação na prática.

"Habitus é um sistema de fortes disposições adquiridas (dispositions), estruturas estruturadas [структурированных структур], destinadas a funcionar como estruturas estruturantes [структурирующих структур], i.e., como princípios que geram e organizam práticas e representações que são objetivamente adaptadas para alcançar certos resultados" (BATURICHIK, 2009). Pode-se dizer que o habitus organiza, arruma, estrutura as energias multidirecionais do agente, compila-as, define-as como certo vetor na direção do objetivo escolhido, possibilitando que práticas sociais tenham significado. Uma vez que o habitus é delineado por todo o ambiente cultural de uma pessoa durante a formação de sua personalidade, torna-se possível falar sobre os diferentes habitus inerentes a diferentes culturas (incluindo diferentes culturas jurídicas), que constituem os tipos correspondentes de homem jurídico.

Outro conceito bourdieano - capital social (BORDIEU, 1993: 56-58) - também pode ser interpretado em termos de antropologia de energia como uma energia de um tipo particular armazenada, alienada de uma pessoa em certa posição social, e que "sob demanda" dela pode ser trazida à tona e implementada como ação social.

Assim, a teoria energética, a despeito de sua inquestionável originalidade e imaginário arcaico, fala a mesma língua que a ciência ocidental moderna, o que nos permite "cruzar" por entre elas. Por sua vez, o enriquecimento da antropologia de energia com as contribuições de cientistas estrangeiros torna possível que se passe de uma "alta teoria" para um estudo direto de empirismo social. Dessa forma, é possível construir a partir dela uma metodologia relevante voltada ao estudo prático do ser humano, o que a torna não apenas uma filosofia "pura", mas também um 
paradigma epistemológico independente, adequado para a construção de uma teoria jurídico-antropológica de "nível médio".

Tudo o que já foi dito não deve ser entendido no sentido de que a antropologia de energia se propõe a ser considerada a partir de agora como a única verdadeira posição filosófica e metodológica, devendo todas as demais ser rejeitadas e esquecidas. Evidentemente que não. Tem-se apenas o fato de que cada pesquisador ou equipe de pesquisa pode explicar claramente (pelo menos para si mesmos e, tanto melhor, para o leitor) o fundamento filosófico sobre o qual suas construções jurídico-antropológicas são edificadas. É impossível argumentar conclusivamente a respeito de uma pessoa-no-direito, sem depender de certas ideias acerca de uma pessoa em geral. Os autores da monografia "Antropologia Sociocultural do Direito" nos deram um exemplo de pesquisa fundamentada em uma nítida concepção filosófica de homem. É claro que outras abordagens da antropologia jurídica, ancoradas em outras teorias filosóficas, também são possíveis (e necessárias).

A aceitação de determinada posição filosófica determina todo o sistema de raciocínio seguinte do pesquisador. "Se antes se supunha que a tarefa da antropologia filosófica fosse 'o estudo da estrutura essencial do homem' (M. Scheler), agora, em contraste, a antropologia deve ser encarregada de investigar a estrutura energética do homem" (KHORUZHY, 2012: 47]. A transição da antropologia filosófica para a "teoria de nível médio", que neste caso é a antropologia jurídica, requer a construção de um discurso científico de acordo com o conceito filosófico escolhido. Essa tarefa não é tão simples como pode parecer à primeira vista. S. Khoruzhy salienta, a esse respeito, que "o avanço da energia para a frente [...] não pode repousar em nenhum aparato conceitual já criado e requer uma reestruturação especial do discurso filosófico" (KHORUZHY, 2012: 44). É possível assumir de bom grado que o discurso científico da antropologia jurídica também deve ser reconstruído, e isso não se refere apenas à terminologia, mas também ao "ângulo de visão" da matéria. E se na filosofia tal reestruturação já foi realizada pelo próprio S. Khoruzhy e sua escola, então, na antropologia do direito, esse trabalho está apenas começando. Como já mostrado, ele 
pode ser feito (pelo menos em parte) usando conceitos desenvolvidos pela ciência universal, desde que sejam adequadamente "traduzidos".

Quanto à segunda metacategoria (o direito), ela "teve mais sorte". Quase todos os trabalhos sobre antropologia jurídica contêm uma definição do direito, a partir da qual o autor caminha. Como já foi observado, há muitas definições a esse respeito. Portanto, não pretendendo escolher a "melhor", tentaremos apenas designar um critério que nos permita cortar aquelas que são certamente inaplicáveis no discurso jurídico-antropológico. Toda concepção positivista ("legalista", nos termos de V. S. Nersesyants) que, de uma forma ou de outra, identifica o direito com o Estado - tratando o direito como "a vontade das classes dominantes", "a norma estabelecida pelo Estado", "a ordem do soberano" etc., conquanto traga consigo uma ampla gama de fenômenos para além do alcance da fenomenologia jurídica, indubitavelmente entra no campo temático da antropologia jurídica.

Depois que as linhas básicas das metacategorias fundamentais de antropologia jurídica foram delineadas, torna-se possível construir um léxico ${ }^{2}$ para essa ciência, isto é, torna-se possível a construção de conceitos que componham a sua linguagem operacional e sejam determinados com base em ideias já formuladas sobre o homem e o direito. Como já mencionado, isso é possível formando "convenções terminológicas" ao final de uma ampla discussão científica. Tal trabalho, em essência, é realizado constantemente. Como exemplos de conclusões terminológicas bem-sucedidas, podemos citar a introdução por O. A. Puchkov do conceito de ambiente jurídico (PUCHKOV, 1999: 142) e o termo subjetivação jurídica proposto por V. I. Pavlov (PAVLOV, 2012 a: 13), tomados da análise social bourdieana dos conceitos de campo jurídico e capital jurídico e, finalmente, a noção de pluralismo jurídico com frequência encontrada nos trabalhos acerca de antropologia jurídica (GRIFFITHS, 1986, p. 2).

2 No original: тезауруса (thesaurus). 


\section{CONSIDERaÇões FINAIS}

Enfatizamos mais uma vez que este artigo é um convite para uma discussão. O autor estabeleceu como objetivo apresentar o problema, mas de modo algum reivindicando uma solução final, pois considera como sendo a tarefa prioritária da antropologia jurídica a superação da "bifurcação" dessa disciplina científica, o que requer uma interação mais ativa de duas comunidades científicas que atualmente agem isoladamente umas das outras.

A necessidade de reinstitucionalização da antropologia jurídica por meio do desenvolvimento de um novo paradigma existe de forma objetiva em ambas as comunidades - a comunidade há muito estabelecida de antropólogos e a comunidade jurídica emergente - embora, talvez, para a primeira não seja óbvio por que exatamente sua existência é relativamente longa e estável, e por que a segunda estaria concentrada na busca ativa de um paradigma. O fato é que a maioria dos membros da comunidade antropológica atua no quadro do paradigma cujos fundamentos se situam na primeira metade do século XX, com os "pais fundadores" da antropologia jurídica - B. Malinowski e outros. Seu núcleo é composto por várias versões dos conceitos de sociedade tradicional e direito consuetudinário, enquanto os representantes da comunidade jurídica estão principalmente interessados na existência jurídica da sociedade moderna (o que alguns autores chamam de "antropologia do direito positivo"). Ao mesmo tempo, uma simples "troca" de conceitos entre essas comunidades não é possível, assim como não é possível a construção de uma nova teoria a partir de fragmentos pontuais (escolhidos mais ou menos arbitrariamente) entre aqueles existentes.

É por isso que é necessário formar um novo paradigma que se tornará um modelo convincente e viável que nos permita explicar de modo simultâneo as "metades" da realidade jurídica, e fornecer a chave para se entender tanto a pessoa-no-direito enquanto um fenômeno humano universal, quanto toda a diversidade de suas manifestações locais culturalmente condicionadas. Não tendo a liberdade de prever como será o "preenchimento" conceitual desse novo paradigma, 
o autor tentou identificar apenas alguns dos seus pontos de referência que lhe parecem críticos, e descrever a direção do possível processo de construção. O progresso nesse caminho exigirá esforços conjuntos de representantes de ambas as comunidades científicas que desenvolvam a antropologia jurídica, o que deverá eventualmente levar à síntese desejada tanto no campo da metodologia quanto da construção de conceitos fundamentais. $\mathrm{O}$ autor espera que este artigo contribua para a ativação desse diálogo.

\section{REFERÊNCIAS}

BATURICHIK, M. V. 2009. Габитус [Habitus]. Disponível em: http://bourdieu.name/content/gabitus-enciklopedija-sociologii . Acesso em: 11. 06. 2016. BOCHAROV, V. V. 2013. Неписаный закон: Антропология права [A lei não escrita: Antropologia jurídica]. São Petersburgo: АИК, 328 p.

BOURDIEU, P. 1993. Социология политики [Sociologia política]. Moscou: Socio-Logos, $336 \mathrm{p}$.

CARBONNIER, J. 1980. Юридическая социология [Sociologia jurídica]. Moscou: Прогресc, 352 p.

GRIFFITHS, J. 1986. What is legal pluralism? // Journal of Legal Pluralism. № 24, p. 1-50.

ISAEV,N. A.; CHESTNOV, I. L. (Org.) 2015. Социокультурная антропология права. Коллективная монография [Antropologia Jurídica Sociocultural: Monografia coletiva] / Под ред. Н. А. Исаева, И. Л. Честнова. São Petersburgo: Алеф-Пресс, 840 p.

KHORUZHY, S. S. 2002. Антропологические следствия энергийной онтологии Православия [Consequências antropológicas da ontologia energética ortodoxa]. Disponível em: http://synergia-isa.ru/lib/download/ lib/019_Horuzhy_Antr_Sled.doc. Acesso em: 11. 06. 2016.

KHORUZHY, S. S. 2012. Исследования по исихастской традиции [Estudos sobre a tradição hesicasta]. T.2. - Санкт-Петербург: Издательство Русской христианск. гуманитарн. Академии, 446 p. 
KOVLER, A. I. 2002. Антропология права [Antropologia jurídica]. Moscou: HOPMA, $480 \mathrm{p}$.

NERSESYANTS, V. S. 1999. Юридическая антропология как наука и учебная дисциплина [Antropologia jurídica como ciência e disciplina acadêmica]. Предисловие [Prefácio] // Рулан, Н. Юридическая антропология. Moscou: HOPMA, p. 1-6.

NOVIKOVA, N. I. 2016. На праве земля держится: юридическая антропология как междисциплинарное исследование [A Terra é mantida suspensa pelo direito: antropologia jurídica como estudo interdisciplinar] // Феномен междисциплинарности в отечественной этнологии // Moscou: ИЭА РАН.122-135.

PAVLOV, V. I. 2012a. От субъекта права к правовой субъективации (к началам энергийно-правового дискурса) [Do sujeito de direito à subjetivação jurídica (ou ao início do discurso energético-jurídico)] // Наука теории и истории государства и права в поиске новых методологических решений. São Petersburgo: Астерион, p. 115-133.

PAVLOV, V. I. 2012b. Энергийно-правовой дискурс как постклассическая антропология права. К началам деконструкции классической модели юридической ответственности [О discurso energético-jurídico como uma antropologia pós-clássica do direito. Pelo início da desconstrução do modelo clássico de responsabilidade jurídica] // Правоведение. Изв. Вузов. № 2, p. 14-39.

PAVLOV, V. I. 2014. Методологические основания антропологической концепции права [Fundamentos metodológicos do conceito antropológico de direito] // Право Украины. № 1, p. 166-181.

PUCHKOV, O. А. 1999. Антропологическое постижение права [Compreensão antropológica do direito]. Ekatarimburgo: Изд-во УрГЮА, 384 р.

PUCHKOV, О. А. 2001. Юридическая антропология и развитие науки о государстве и праве: Теоретические основы [Antropologia jurídica e desenvolvimento da ciência sobre o Estado e o Direito: fundamentos teóricos]. Дис... доктора юрид. наук. Ekaterimburgo, 502 p. 
ROULAND, N. 1999. Юридическая антропология [Antropologia jurídica]. Moscou: HOPMA, $310 \mathrm{p}$.

ROULAND N. 1990. L'anthropologie juridique, Que sais-je? Paris: Les Presses universitaires de France, $127 \mathrm{p}$.

RYAZANOVA, S. В. 2013. Категориальный аппарат религиоведения: границы, принципы, парадигмы [Араrato categórico de estudos religiosos: limites, princípios, paradigmas] // Научный ежегодник Института философии и права Уральского отделения Российской академии наук, Том 13. Вып. 1, p. 37-54.

SHMATKO, N. А. 1993. Введение в социоанализ Пьера Бурдьѐ [Introdução à análise socio-analítica de Pierre Bourdieu] // Бурдье, П. Социология политики. Moscou: Socio-Logos, p. 7-25.

SOKOLOVSKY, S. В. 2000. О возможностях диалога юристов и антропологов (терминологические заметки) [Sobre as oportunidades de diálogo entre juristas e antropólogos (notas terminológicas)] // Юридическая антропология. Закон и жизнь. Moscou: Институт этнологии и антропологии РАН, p. 51-62.

SOKOLOVSKY, S. В. 2015. Российская антропология: современная проблематика и дисциплинарное устройство [Antropologia russa: problemática moderna e aparato disciplinar] // Этнометодология: проблемы, подходы, концепции. Вып. 19. Moscou: 97 Наследие ММК, p. 132-168.

\section{SOBRE O AUTOR:}

\section{Pavel Igorevich Kostogryzovi}

Doutor em Ciências Históricas, Pesquisador do Instituto de Filosofia e Direito da Filial Ural da Academia Russa de Ciências, Professor Sênior do Departamento de História do Estado e do Direito da Universidade Estatal de Direito dos Urais. Email: pkostogryzov@yandex.ru.

Submetido em: 28-2-2018

Aceito em: 13-4-2018 